Images dans le monde ibérique et ibéricoaméricain

9 | 2016

Innovations politiques et culturelles dans les pays andins

\title{
La nueva burocracia plurinacional en Bolivia
}

\section{Ximena Soruco Sologuren}

\section{(2) OpenEdition}

\section{Journals}

Edición electrónica

URL: http://journals.openedition.org/agedor/1177

DOI: 10.4000/agedor. 1177

ISSN: 2104-3353

Editor

Laboratoire LISAA

Referencia electrónica

Ximena Soruco Sologuren, «La nueva burocracia plurinacional en Bolivia », L'Âge d'or [En línea],

9 | 2016, Publicado el 01 marzo 2016, consultado el 20 abril 2019. URL : http://

journals.openedition.org/agedor/1177; DOI : 10.4000/agedor.1177

Este documento fue generado automáticamente el 20 abril 2019.

L'Âge d'or. Images dans le monde ibérique et ibéricoaméricain 


\title{
La nueva burocracia plurinacional en Bolivia
}

\author{
Ximena Soruco Sologuren
}

1 Los estudios sobre la burocracia suelen concentrarse en las normas, procedimientos, decisiones y gestión de la institución estatal o en los sistemas de reclutamiento y capacidades de los funcionarios públicos pero menos en su composición social: se presume que la socialización en la función y la institución hacen irrelevante el origen social del burócrata. Sin embargo hay razones de peso para estudiar la composición social de la burocracia, tema del presente artículo. Una de ellas se vincula con el análisis de la movilidad social ascendente que conlleva "pertenecer al Estado", más aún en contextos en los cuales la educación superior - licenciatura es la condición mínima de ingreso a la burocracia, salvo para puestos auxiliares que requieren al menos bachillerato - es de acceso gratuito como en América Latina y el empleo público ofrece la estabilidad que no logra generar el privado, marcado por una creciente informalidad. Se trata, en verdad, del viejo tema de Rojo y negro (1830), la novela de Stendhal en la que el protagonista, Julien Sorel, hijo de campesinos, logra encumbrarse en la cúspide de la sociedad parisina del siglo XIX como letrado.

2 En Bolivia, el recuento crítico del ascenso social del abogado cholo, "arribista y traidor por naturaleza" queda registrado en El cholo Portales, la novela de Enrique Finot publicada en 1926. Si bien se trata de una temática reiterada en la literatura boliviana, ha sido poco estudiada durante el siglo XX y está pendiente captar sus alcances en el actual proceso de cambio (así como en otros procesos políticos latinoamericanos), más cuando esta transformación política coincidió con un ciclo de crecimiento económico desconocido en la historia boliviana.

3 La segunda razón para estudiar la composición social de la burocracia boliviana es su escasa estabilidad. Esto se debe a que no hay una carrera del funcionario público, los cargos son de libre remoción y es frecuente la rotación: entre el 30 y el $40 \%$ de los funcionarios encuestados no tiene más de un año en el cargo. Esto, por supuesto, atenta contra la consolidación de la burocracia. Esta debilidad puede ser, sin embargo, también una ventaja: los órganos Ejecutivo y Legislativo no se han convertido en entes 
corporativos cristalizados y de escasa posibilidad de reforma, como pasó con las FFAA, la policía, la universidad pública, etc. Por el contrario, los vientos de cambio social, como la emergencia indígena desde la década de 1990, ingresaron al Estado a través de elecciones, pero también mediante un sistema poco institucionalizado de reclutamiento de personal, por el cual la autoridad electa nombra a "su" personal. La contracara de esta democratización es el clientelismo.

El libro Composición social del Estado plurinacional ${ }^{1}$, cuyos hallazgos resumimos aquí, tuvo como objetivo analizar el nuevo Estado desde una perspectiva que pueda ir más allá de los discursos sobre lo plurinacional y mirarlo desde sus prácticas concretas. Una de ellas es la dinámica de la burocracia que lleva a la pregunta sobre quiénes son los funcionarios públicos en la actualidad y qué cambió respecto al pasado en términos de composición étnica y social del funcionariado.

5 Esta pregunta se expresa en una indagación sobre el perfil del servidor público: edad promedio, proporción entre hombres y mujeres, nivel educativo alcanzado, autoadscripciones étnicas, pertenencia a organizaciones sociales y variaciones de estas características según los cargos ocupados. ¿Estamos hablando de un nuevo funcionario público?, ¿qué repercusiones tiene esta novedad en la burocracia? ¿Se ha profundizado la presencia indígena?, ¿qué cambios se evidenciaron en la composición de las autoridades elegidas, en diferentes niveles, desde las elecciones municipales de 1995, tras la Ley de Participación Popular, estudiadas por Albó ${ }^{2}, \mathrm{Ayo}^{3}$ y otros autores, y luego en la Asamblea Constituyente y la Asamblea Legislativa Plurinacional ${ }^{4}$ ? Si el discurso plurinacional se verifica, la presencia indígena habría ido trascendiendo el ámbito municipal y rural para abarcar también los niveles departamental y central asentados en las ciudades, y en los funcionarios designados, en quienes - a diferencia de los funcionarios elegidos que emplean las adscripciones étnicas como capital electoral - cabría esperar menores incentivos para mantener su identidad.

6 Para responder a estas preguntas se realizó una encuesta a todos los funcionarios presentes en tres instituciones públicas, entre septiembre y octubre de 2013: el municipio urbano de La Guardia, ubicado en el departamento de Santa Cruz, la gobernación de Chuquisaca asentada en la ciudad de Sucre y el Ministerio de Educación en La Paz, con un total de 1.174 encuestados. Esta encuesta fue luego comparada con información de las tres instituciones arrojada por el (único) Censo de Funcionarios Públicos, confeccionado en 2001, para observar los cambios en una década. Los casos fueron elegidos por razones geográficas: corresponden al altiplano, la región de valles y el oriente boliviano, como a niveles: central (ministerio), departamental (gobernación) y municipal. Otro criterio fue el grado de institucionalización: el ministerio de educación existe desde la fundación de la república, sus labores y procedimientos han sido establecidos al menos desde 1952, cuando se masifica la educación pública y en el actual régimen (2006-2015) ha tenido pocos cambios de autoridad ( 3 ministros). La gobernación de Chuquisaca, antes prefectura, se ubica desde la guerra civil de 1899 que cambia la sede de gobierno a La Paz, en el edificio que fuera la Casa Presidencial de la República. El estancamiento económico de la región confiere una enorme centralidad al aparato público como fuente de empleo formal (universidad pública, Corte Suprema, alcaldía, gobernación), y por lo tanto de reproducción de la élite local (clase media profesional) que desde 2006 está siendo disputada por los campesinos que ganan la gobernación el 2010. Sucre es la ciudad donde se inicia y se bloquea la culminación de la Asamblea Constituyente (2006-2009) que se trasladará a Oruro, por tanto, se convierte en el epicentro de la crisis política que en su 
versión radical plantea la secesión por la vía armada. Finalmente, el municipio de La Guardia, zona de expansión de la ciudad de Santa Cruz y próspero comercio agrícola y de bienes raíces, vive en la inestabilidad política por una disputa entre la élite local y los comerciantes y transportistas indígenas, hijos de migrantes de la zona andina.

7 Estos estudios de caso no expresan una tendencia nacional, pero sirven de indicio para seguir estudiando el tema en un contexto donde no existe una institución que centralice las cifras de la burocracia, salvo las nóminas de sueldos del Ministerio de Economía, agregadas además para los niveles sub-nacionales.

8 Fueron dos las constataciones centrales a las cuales la investigación llegó. La primera refiere la democratización en el acceso a la función pública materializada en una mayor presencia de mujeres, jóvenes e indígenas en 2013 respecto a 2001 en las instituciones estudiadas, y una significativa presencia de servidores públicos (9 de cada 10) cuyos padres no fueron burócratas y tuvieron un rendimiento educativo muy inferior a sus hijos.

El segundo argumento es que este nuevo servidor público está en proceso de movilidad social intergeneracional, pero también en relación con sus contemporáneos. Ello conduce a replantear los términos bajo los que se piensa "lo indígena" - un campesino con escasa escolaridad y pobre -, porque también existe un segmento de administradores públicos indígena, joven, urbano, con nivel educativo y cargos similares al funcionario no indígena, mejor remuneración que en el pasado y cambios en los patrones de consumo (crédito de vivienda, seguro social y médico, ocio). Pese a su modernización, este servidor público plurinacional es bilingüe y orgánico - articulado a una organización social - y por lo tanto mantiene marcas de su cultura y desde ella recrea la institucionalidad burocrática, lo que remite a una descolonización del hacer burocrático.

\section{Dimensionar la burocracia}

10 Antes de iniciar el análisis de los resultados de la encuesta es necesario precisar la dimensión del aparato público en Bolivia, a partir del número de funcionarios públicos en 2001 y en 2013 y la renta interna del Estado y del gasto en remuneraciones (sector público no financiero). 
Gráfico 1: Número de funcionarios públicos en el nivel nacional (2001 y 2013)

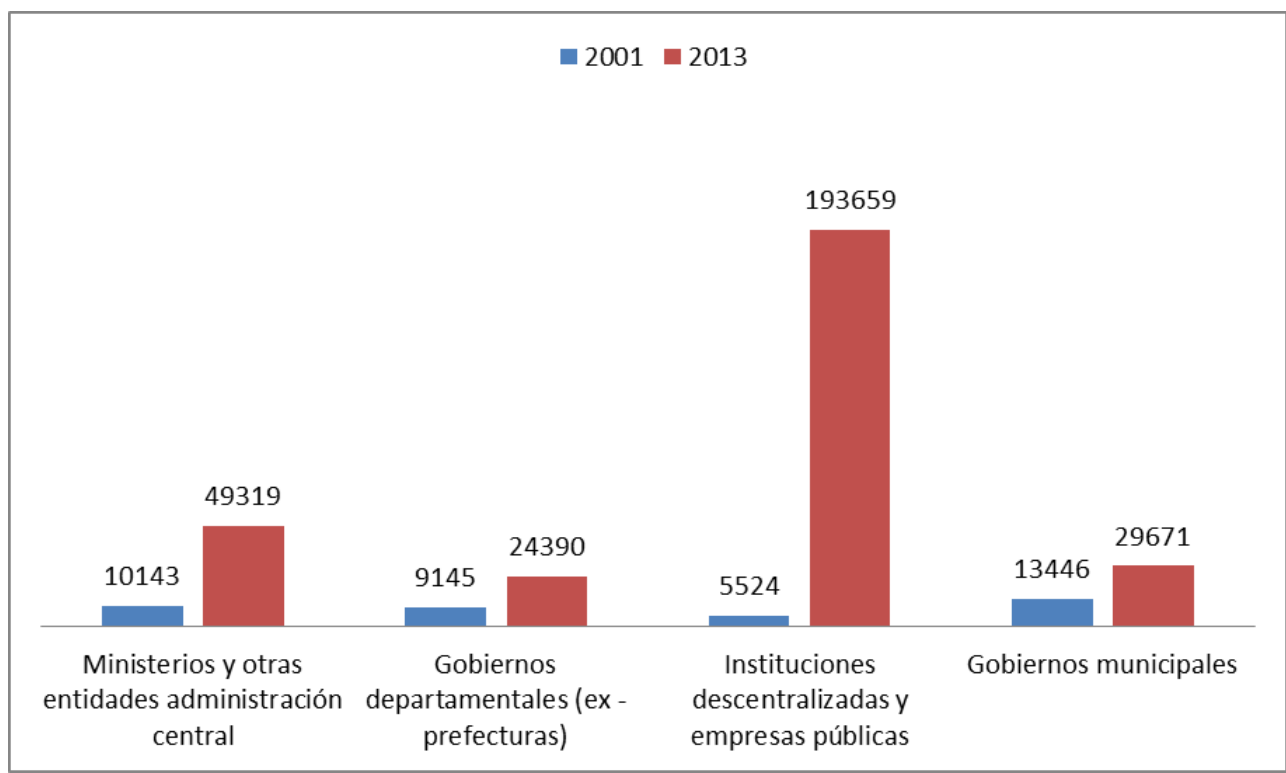

Fuente: Elaboración propia con base en Registro nacional de funcionarios públicos, SNAP-INE, 2001 y Base de datos de empleados públicos, Ministerio de Economía, 2013.

11 En 2001, el número total de funcionarios públicos era de 38.258 y en 2013 asciende a 297.039, lo que representa una tasa de crecimiento promedio anual de 56\% (676\% durante todo el ciclo). De los cuatro sectores públicos, el que ha crecido más es el de las instituciones descentralizadas y las empresas estatales, debido al cambio de modelo económico centrado en el Estado operado bajo el gobierno de Evo Morales desde 2006 (especialmente asociado a su política de nacionalizaciones y creación de varias empresas estatales). El segundo sector en crecimiento es el de la administración central, seguido de las gobernaciones y municipios, como puede verse en el gráfico 1.

Esta aproximación parte del supuesto que el crecimiento de la burocracia no es malo o bueno en sí mismo, sino que debe vincularse con información sobre los ingresos del Estado para ver qué porción ocupa en el total de gastos, si genera déficit fiscal, que fue un problema endémico del Estado boliviano durante los siglos XIX ${ }^{5}$ y XX, y si su crecimiento indica una mayor presencia estatal en términos de servicios y de extensión territorial, que fue también históricamente débil ${ }^{6}$.

13 En términos generales, una burocracia mínima (modelo neoliberal) podría interpretarse como "eficiente" pero también como la expresión de un Estado débil, centralizado y con un rol debilitado, incluso como Estado regulador. Una burocracia pesada (como la de los denominados "socialismos reales") puede convertirse en un freno a la dinámica económica y una mole cara e incapaz de cumplir con sus tareas básicas. Pero si el objetivo es lograr una proporción adecuada entre ingresos estatales, servicios brindados (tipo de gasto), número óptimo de administradores, esto no es una medida fácil de calcular y mucho menos de gestionar. ¿Cómo funciona esta relación en las últimas décadas en Bolivia?

14 Un indicador de la capacidad del Estado para generar sus propios ingresos, que no dependen del precio y cantidad de exportación de las materias primas o de las importaciones (impuestos aduaneros), es la renta interna que obtiene del impuesto al valor agregado (IVA), a las transacciones, al consumo específico, el régimen 
complementario al IVA y otros impuestos municipales y a las transacciones financieras. Con esta medida se compara el gasto público en salarios del sector público no financiero, que incluye las empresas públicas y los sectores de salud y educación.

Así, entre 1990 y 1994 la generación de ingresos por impuestos internos era menor a la erogación en salarios, a partir de 1995 el Estado logra recaudar un poco más de lo que gasta en los sueldos de la burocracia, pero la diferencia se hace mayor en 2003 y desde 2006: la tendencia es a un incremento acelerado del ingreso por impuestos internos (177.331 millones de bolivianos en 2012) en comparación con el crecimiento más modesto del gasto en salarios (91.396 millones de bolivianos en el mismo año) ${ }^{7}$ y esto da sostenibilidad (y en principio racionalidad) a ese crecimiento estatal.

\section{El perfil social del servidor público}

Con esta caracterización del tamaño y gasto de la burocracia nacional, pasamos a describir los datos de la encuesta a funcionarios públicos en 2013 y su comparación con el Censo de 2001.

17 Mujeres. Actualmente hay un avance en la equidad de género en las instituciones públicas estudiadas, aunque las mujeres no llegan al $50 \%$ : 671 son hombres (58\%) y 481 mujeres ( $42 \%)$.

18 Jóvenes. Esta es la variable demográfica más llamativa del nuevo funcionario público. Se trata de un cambio generacional progresivo. Del total de servidores de 2001 y 2013, el segmento poblacional más numeroso es el de 31 a 40 años; en 2013 tres de cada diez funcionarios se ubicaban en ese rango etario frente a 2 en 2001. Disminuyó el grupo de 41 a 50 años y el de 51 a 60 no varió. Hay una característica particular de los jóvenes burócratas del Estado plurinacional en relación con períodos anteriores: pese a estar insertos en un proceso de movilidad social ascendente (son ya citadinos, profesionales y con un empleo formal de "cuello blanco") no abandonan ciertas marcas de sus orígenes, es decir, no solo no están compelidos a negar o esconder su procedencia étnica, sino que la reivindican.

19 La correlación entre segmentos jóvenes y nivel profesional superior muestra que los "hijos del proceso de cambio" tienen mayores niveles educativos que la generación que propició las actuales reformas: Evo Morales nació en 1959, Álvaro García Linera en 1962, la mayoría de los ministros, senadores y diputados o los fundadores del instrumento político tienen hoy más de 50 años, y puede observarse una progresiva tendencia al incremento del nivel educativo en el Estado, entre funcionarios designados. Esto incluye a las mujeres profesionales, jóvenes y auto-indentificadas indígenas.

Indígenas. "La burocracia representa el entorno blancoide de Evo Morales", señalan las críticas dentro y fuera del gobierno; "es el sector tecnócrata - y por lo tanto no indígena que realmente gobierna"8. Pero los datos relativizan estas percepciones, al menos en las instituciones estudiadas: en 2013, 63 \% del total de servidores públicos se declara indígena en la Gobernación de Chuquisaca, 45 \% en el Ministerio de Educación y 18 \% en La Guardia y haciendo la estimación ponderada de las tres instituciones tenemos un 46\% (527 personas) de servidores declarados indígenas, quechuas y aymaras. 
Gráfico 2: Autoadscripción étnica del servidor público según escolaridad, 2013 (\%)

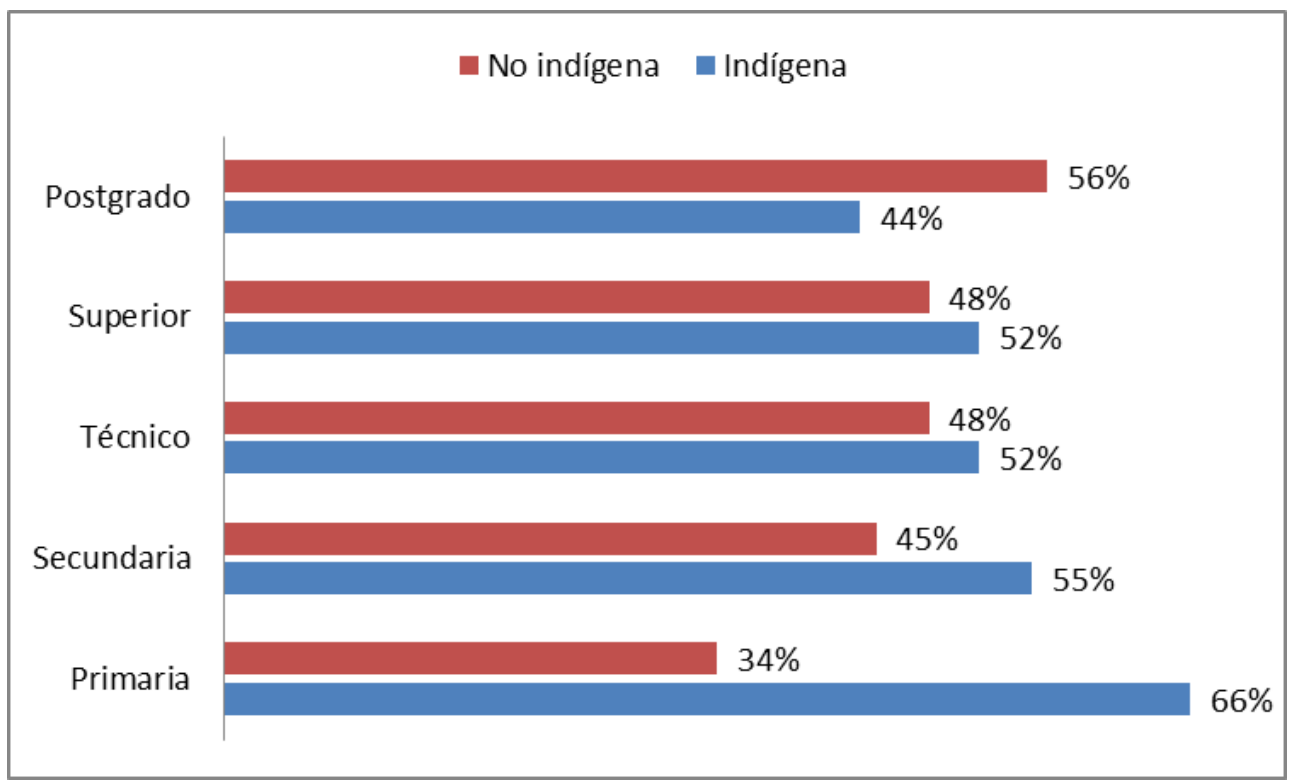

Fuente: Elaboración propia con base en la Encuesta a servidores públicos, CIS, 2013.

Más sorprendente aún es que al comparar nivel educativo con autoadscripción étnica, se observa que existen más funcionarios indígenas técnicos y licenciados que no indígenas. Esta ventaja se invierte en los extremos de la escolaridad, primaria y postgrado. En el primer caso porque se trata de funcionarios en el rango etario de 61 años en adelante, generación para la cual la brecha educativa entre indígenas y no indígenas era elevada.

Gráfico 3: Autoadscripción étnica del servidor público según su cargo, 2013 (\%)

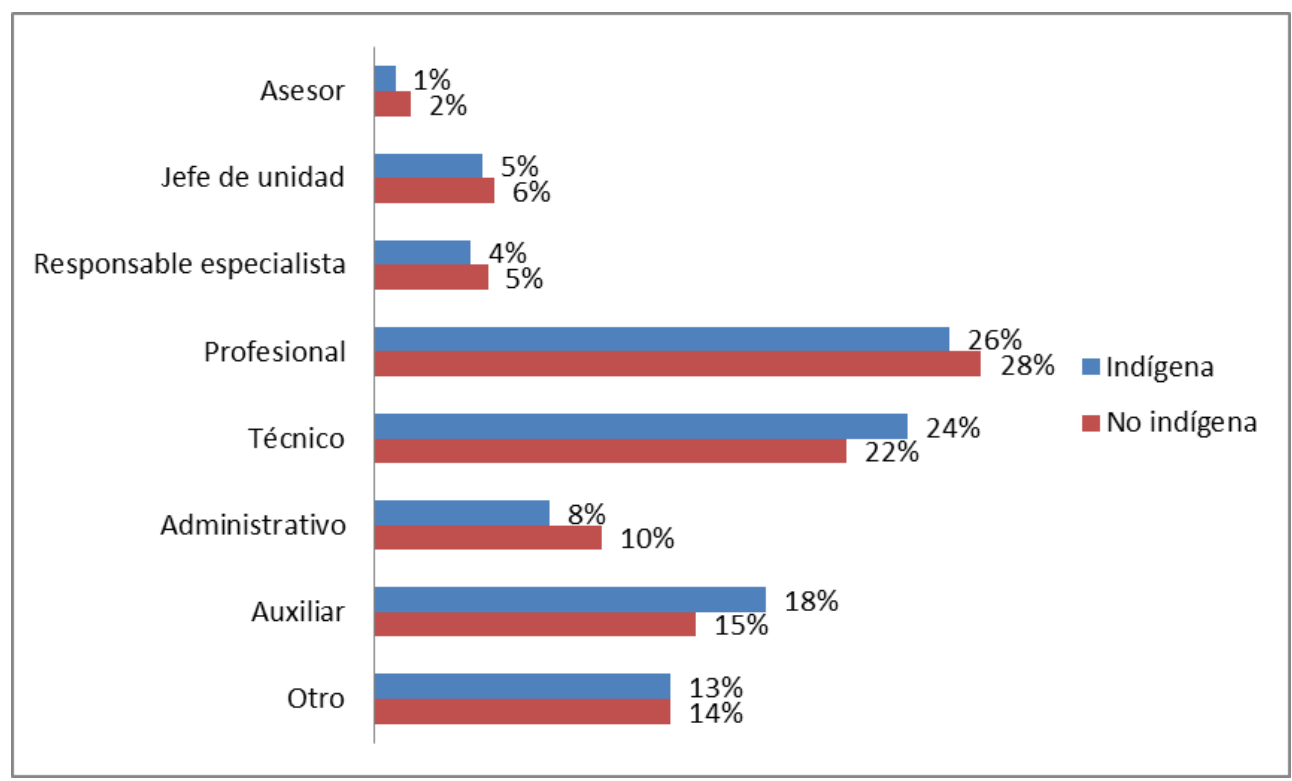

Fuente: Elaboración propia con base en la Encuesta a servidores públicos CIS, 2013. Los nombres de los cargos corresponden a la denominación del Estado boliviano.

La diferencia étnica en la distribución de puestos públicos se reduce más que el nivel educativo, no pasando de tres puntos porcentuales en ninguno de ellos (gráfico 3). En el 
caso del Gobierno Autónomo de Chuquisaca, la preminencia indígena en los cargos es mayor que la no indígena: $73 \%$ de los jefes de unidad se autoadscribe quechua, aunque también hay presencia indígena mayoritaria en los cargos "técnico" (71\%) y "auxiliar" (68 \%) y minoritaria en los cargos administrativos (46\%).

Escolaridad. Pese a que se cuestiona con frecuencia que el costo de la democratización de la burocracia ha sido la disminución del reclutamiento meritocrático y por tanto, del nivel educativo entre los funcionarios, nuestra encuesta muestra que no solo se ha mantenido el nivel profesional de los servidores, sino que la titulación de posgrado se ha incrementado en diez puntos porcentuales con respecto a 2001. Comparando el nivel educativo de los funcionarios indígenas y no indígenas, existen más indígenas burócratas con niveles de escolaridad secundario, técnico y superior y este dato es importante porque está mostrando que no hay contradicción, sino posiblemente coincidencia, entre un mayor nivel educativo y la conciencia de pertenencia étnica, y que por tanto la relación de décadas pasadas indígena $=$ pobre $=$ rural $=$ bajo nivel educativo se está modificando a favor de un perfil indígena urbano, letrado, con mayores ingresos económicos y en este caso, funcionario público, lo que podría estar constituyendo uno de los segmentos emergentes de la nueva clase media.

\section{Filiación partidaria y sindical}

Del total de encuestados que indica militar en el partido de gobierno, la mitad corresponde al Ministerio de Educación, seguido del municipio de La Guardia (41 \%), con un sorprendente $9 \%$ para la Gobernación de Chuquisaca, la entidad con mayor proporción de funcionarios autoidentificados indígenas. Al relacionar filiación e identidad étnica se observa que no existe mucha diferencia: los militantes indígenas representan el $53 \%$ frente a los militantes no indígenas ( $47 \%$ ), mientras que hay más simpatizantes e "invitados" al MAS que no son indígenas.

Respecto a la pertenencia de los funcionarios públicos a una organización social (sindicato, gremio, asociación), el $37 \%$ manifestó pertenecer, lo que es una cifra importante considerando que se trata de la burocracia estatal -este crecimiento de los funcionarios con militancia social/sindical es una de las características del proceso abierto en 2006. Al mismo tiempo, la "organicidad" sindical está más vinculada a la autoadscripción étnica indígena ( $65 \%$ de los indígenas pertenece a una organización social), aunque es llamativo que la mitad de quienes no se autoadscriben indígenas también pertenece a una organización social, lo que evidencia que la integración a agrupaciones sociales no es una característica solo indígena.

La importancia de esta participación sindical no disminuye ni con la escolaridad ni con el cargo del funcionario público, lo que muestra que es compartida por estos nuevos funcionarios, incluso por encima de la militancia política, como sucede con claridad en la Gobernación de Chuquisaca.

\section{Movilidad social intergeneracional}

La democratización del Estado iniciada por la vía de la municipalización, las diputaciones uninominales y otros mecanismos de descentralización impulsados en los años 90, así como el recorrido político exitoso del Movimiento al Socialismo-Instrumento Político por 
la Soberanía de los Pueblos (MAS-IPSP), liderado inicialmente por los cocaleros pero que crece en organizaciones y actores del ámbito rural al urbano, tienen un antecedente sociológico que es importante mencionar: la intensa migración campo-ciudad desatada tras la reforma agraria de 1953, producto de la Revolución Nacional ocurrida el año anterior. Este proceso migratorio - producto de la desarticulación de la hacienda, la educación de masas y el minifundio - se interrumpe y parece frenarse con la crisis económica de 1982-85 para recuperarse y plantear mayores expectativas -frustradas- de movilidad social en la década de 1990.

Pese a estos altibajos, los últimos sesenta años son testigos del cambio sociológico del componente indígena de la sociedad boliviana, con características inéditas en el contexto de modernización latinoamericana. La transición rural-urbana en el continente, la masificación de las ciudades, los procesos siempre tensos de integración de estas nuevas masas urbanas y los fenómenos políticos que generaron conforman un modelo de progresiva homogeneización cultural urbana ${ }^{10}$ en torno al mestizaje y al abandono paulatino de la cultura rural (como en el caso de los gauchos, llaneros, rotos, campesinos blancos y mestizos) y de la cultura indígena. De ahí que el término indígena solo sobreviva en la región si está vinculado al de campesino (agricultor) y al del área rural.

Desde la colonia, la ciudad latinoamericana ha sido sinónimo de no-indígena o incluso de anti-indígena. Así, el poblamiento urbano, sin importar demasiado el tamaño, implica la noción de "vecino" o "misti" (mestizo), un sujeto que niega su origen y se siente superior al indígena. Por su parte, el indígena debe mestizarse cuando sale de su comunidad rural y su actividad agropecuaria rumbo a los pueblos y ciudades como única posibilidad de movilidad social.

En Bolivia, en cambio, en diferentes tiempos, ritmos e intensidades se ha producido la migración campo ciudad, pero su significación cultural ha sido distinta: la resistencia cultural, la capacidad organizativa y la proyección política indígena y campesina, de la que el MAS-IPSP es una expresión, se desarrolló en paralelo a la debilidad de las élites para generar un modelo cultural al que imitar, así como a su pobre desenvolvimiento en el mercado y a su incapacidad en la conducción estatal, lo cual generó las condiciones de expansión de la cultura indígena hacia las ciudades y su pervivencia (no sin transformaciones) en ámbitos urbanos.

31 Con el objetivo de entender la movilidad social por la vía de la burocracia, se les preguntó a los servidores públicos encuestados datos sobre sus padres. La comparación entre las trayectorias laborales y educativas de ambas generaciones resultó ilustrativa de la emergencia de este nuevo sujeto social: joven, indígena, con altos niveles de educación y en proceso de ascenso social.

Ocupación de los padres del servidor público, 2013 (\%)

\begin{tabular}{|l|l|l|l|l|}
\hline & \multicolumn{2}{|l|}{ Padre } & \multicolumn{2}{l|}{ Madre } \\
\cline { 2 - 5 } & Frecuencia & $\%$ & Frecuencia & $\%$ \\
\hline Servidores públicos & 20 & $4 \%$ & 1 & $0 \%$ \\
\hline Profesionales & 114 & $26 \%$ & 75 & $16 \%$ \\
\hline
\end{tabular}




\begin{tabular}{|l|l|l|l|l|}
\hline Empresarios & 7 & $2 \%$ & 2 & $0 \%$ \\
\hline Comerciantes & 31 & $7 \%$ & 65 & $14 \%$ \\
\hline Oficios manuales & 143 & $32 \%$ & 29 & $6 \%$ \\
\hline Servicios & 35 & $8 \%$ & 21 & $5 \%$ \\
\hline Trabajadores agropecuarios & 93 & $21 \%$ & 28 & $6 \%$ \\
\hline Labores del hogar & 4 & $1 \%$ & 243 & $52 \%$ \\
\hline Total & 447 & 100 & 464 & 100 \\
\hline
\end{tabular}

Fuente: Elaboración propia con base en la Encuesta a servidores públicos, CIS, 2013.

Un dato fundamental que apoya la hipótesis de un nuevo funcionario público aquí planteada es que solamente el $4 \%$ de los padres de los servidores públicos actuales, y ninguna madre, tuvo como ocupación principal la burocracia, es decir, no se ha heredado el acceso a este puesto por la vía de las redes familiares. Así, la actividad más recurrente del padre del actual servidor público es la de "oficios manuales" ( $32 \%$ ), seguido de actividades profesionales (26\%) y trabajo agrícola (21\%), como se observa en el cuadro 1 . Se tienen entonces, padres de funcionarios que son o fueron artesanos y obreros, campesinos y profesionales. En el caso de las madres, un $52 \%$ se dedicaba a las labores de casa, seguido de un $16 \%$ profesional y un $14 \%$ comerciante. Estos datos permiten concluir que tanto en términos de ocupación como de escolaridad se evidencia un proceso de movilidad social ascendente de los actuales funcionarios públicos con relación a sus padres. Y dada la importancia de la educación en este rubro, la apuesta por la profesionalización de una generación a la otra es clave para el acceso a estos puestos $y$, por lo tanto, para la movilidad por la vía del Estado. Este hecho explicaría en parte los rechazos o dudas de algunos municipios rurales a transformarse en autonomías indígenas, ya que estos jóvenes mejor educados no podrían aprovecharse de sus credenciales educativas en un sistema de "usos y costumbres" en el que se privilegia la rotación en los cargos en beneficio de los mayores ${ }^{11}$.

Sin embargo, el hecho de que esta sea la primera generación profesional y con trabajo en la gestión pública no genera, como probablemente sucedía en el pasado, una negación y abandono de la cultura de los padres. El mestizaje (blanqueamiento) ya no es la condición para este ascenso, como indica la alta proporción de burocracia adscrita a un pueblo o nación indígena y su vínculo con organizaciones sociales. Quizá esta sea la característica determinante del gobierno de Evo Morales: generar un proceso de modernización pero con una impronta indígena, que ya no exige negar el origen ni desear una nueva identidad que no se logra, es decir, la descolonización en este contexto podría significar potenciar al sujeto en la medida de librarlo de la escisión identitaria que a través del mestizaje caracterizó la modernidad latinoamericana. 


\section{Institucionalidad} cargo en 2010, el tiempo de permanencia es similar al registrado en 2001 (43\% con menos de un año en 2013 frente al $39 \%$ en 2001), lo que muestra la elevada rotación de los servidores públicos al menos en el nivel subnacional, aunque permanezcan los mandos superiores (gobernador, alcalde). El ministerio de Educación tiene el menor porcentaje de rotación de las tres instituciones tanto en 2001 como en 2013, e incluso con una baja en este último año. Sin embargo, solo el $11 \%$ de sus funcionarios ha llegado a permanecer tres años, lo cual muestra la profunda debilidad de la burocracia para transmitir experiencia: cuando llega a aprender mínimamente sus funciones el funcionario es removido de su cargo.

Pero, ¿es tan inestable el empleo público en Bolivia? Hay dos aspectos que matizan la respuesta. Tanto en 2001 como en 2013 se observa una importante rotación de los funcionarios entre varios cargos en la misma institución (un tercio en La Guardia, 40 \% en la gobernación de Chuquisaca y 51 \% en el ministerio de Educación en 2001). Sin embargo, estos porcentajes de rotación y por tanto de permanencia más prolongada en la institución pública han disminuido en 2013, curiosamente no en La Guardia, pero sí en la Gobernación y en el Ministerio, lo que implica un menor tiempo de permanencia del servidor público en la institución y por tanto menos posibilidad de acumular experiencia y emplearla en las funciones públicas.

39

L'Âge d'or, 9 | 2016 
instituciones trabajó antes en otra institución pública. La institución pública empleadora corresponde al nivel central (66\%) y en menor medida al nivel municipal $(17 \%)$ y de gobernación ( $9 \%$ ), lo que permite suponer que la rotación de los actuales servidores no es solo entre cargos en una misma institución sino entre instituciones en un mismo gobierno (desde 2006, en este caso).

Dados estos resultados - escaso tiempo de permanencia en el cargo, rotación dentro de la misma institución, evidencia de rotación entre instituciones similares durante el mismo gobierno - es necesario seguir estudiando la dinámica de cambio y permanencia de los servidores públicos en la burocracia boliviana para no sacar falsas conclusiones. Quizá el movimiento del funcionario público se de en conglomerados: cuando se traslada a un jefe de unidad, un coordinador, responsable o una autoridad que tiene un equipo a su cargo, así como a un viceministro y a un ministro, se llevan a su grupo de trabajo a otra unidad dentro de la misma institución o a otra institución. No se trataría, entonces, de servidores públicos que estuvieron durante menos de un año en su cargo y que hacen inviable la burocracia racionalizada, como la pensaba $W_{e b e r}{ }^{12}$, sino de dinámicas particulares a nuestro tejido social, rotaciones quizá grupales entre unidades y entre instituciones del Estado.

41 Tampoco es posible considerar que la carrera del funcionario público de por vida - es decir, un equipo técnico exento de las luchas políticas electorales, especializado y tan eficiente que incluso se convierte en una jaula de acero que controla al propio político que está encima suyo por su permanencia y eficiencia - lo soluciona todo. De hecho, si comparamos las instituciones públicas bolivianas en las que hay carreras de funcionarios - universidades, magisterio, policía y FFAA - es fácil percibir la deficiencia de estos aparatos pesados e inertes, casi imposibles de transformar. Los poderes Ejecutivo y Legislativo en cambio, pese a la rotación de cargos y la inestabilidad laboral, han sido los primeros en responder a las presiones de democratización de la sociedad boliviana, con el diseño normativo que lo posibilita y luego con la potestad de los elegidos de designar a los funcionarios públicos que llevan adelante las normas y proyectos sancionados. Quizá esto no hubiera sido posible, o no tan deprisa, con empleados públicos vitalicios en sus cargos.

La contracara de esta democratización de la burocracia es la precariedad laboral, contratos cortos, con muchos consultores en línea y por producto que no tienen los beneficios de los servidores de planta y sin el derecho a la sindicalización para los funcionarios, suprimido en la era neoliberal pero continuado en el actual gobierno. Además, el aparato público requiere mayor institucionalización para racionalizarse, ser eficiente y permanecer en el tiempo, lo que a su vez supondría un cierre a la democratización que ha logrado. Este dilema de apertura (democratización) y cierre (institucionalización) es de difícil solución y continúa siendo parte de las tensiones del proceso de cambio boliviano. 


\section{NOTAS}

1. SORUCO Ximena, FRANCO Daniela y DURÁN Mariela, Composición social del Estado plurinacional. Hacia la descolonización de la burocracia, CIS, La Paz, 2014.

2. Xavier ALBÓ Xavier: “Alcaldes y concejales campesinos/indígenas. La lógica tras las cifras”, in Secretaría Nacional de Participación Popular, Indígenas en el poder local. La Paz, 1997; Ojotas en el poder local: Cuatro años después. CIPCA, La Paz, 1999; ALBÓ Xavier y La Paz, QUISPE Víctor. Quiénes son indígenas en los gobiernos municipales. CIPCA-Plural, La Paz, 2004.

3. AYO Diego, Democratizando la democracia. Una mirada a la Participación Popular en los albores de una Bolivia de las Autonomía, PNUD, La Paz, 2009.

4. AREQUIPA Marcelo, "La configuración del poder político: estudio acerca del reclutamiento, selección y producción legislativa de las élites políticas en Bolivia (1985-2009)”, tesis doctoral, Universidad Autónoma de Madrid, Madrid, 2013; GONZALES Inès (comp.), Biografías. Historias de vida en la Asamblea Legislativa Plurinacional, IDEA-FES-ERBOL-Gente Común, La Paz, 2013; CHÁVEZ Patricia, ¿De la colorida minoría a una mayoría gris?: presencia indígena en el legislativo, Fundacion Friederich Ebert-Gente Común, La Paz, 2012; ZEGADA María Teresa y KOMADINA Jorge, El espejo de la sociedad. Poder y representación en Bolivia, Ceres-Plural, La Paz, 2014.

5. PERALTA Víctor, El poder burocrático en la formación del Estado moderno. Bolivia, 1825-1890, tesis de maestría en historia andina, FLACSO sede Ecuador, Quito, 1992.

6. Programa de Naciones Unidas para el Desarrollo, El estado del Estado en Bolivia. Informe nacional sobre desarrollo humano en Bolivia, PNUD, La Paz, 2007.

7. Instituto Nacional de Estadística (INE), 2014. Cifras en bolivianos de 1990.

8. V. por ejemplo, la revista Willka titulada "Evo Morales entre: entornos blancoides, rearticulación de las oligarquías y movimientos indígenas", №1, Centro Andino de Estudios Estratégicos, El Alto, primer semestre de 2007.

9. Los invitados son generalmente integrantes de las clases medias - a menudo periodistas, cantantes, rectores de universidades, etc. - que no son parte orgánica del MAS y que ocupan cargos en las listas de candidatos a invitación de Evo Morales (v. por ejemplo, Hervé Do Alto, "Un partido campesino en el poder. Una mirada sociológica del MAS boliviano”, en Nueva Sociedad № 234, Caracas, julio-agosto 2011).

10. ROMERO José Luis, Latinoamérica; la ciudad y las ideas, Siglo XXI, Buenos Aires, 2011.

11. CORDERO PONCE V. Sofía, Estado plurinacional y autodeterminación en Bolivia y Ecuador: experiencias de construcción de autogobierno indígena, tesis de Doctorado, Flacso, sede Ecuador, Quito, 2015.

12. WEBER Max, Economía y sociedad, FCE, México, 2004 [1922].

\section{RESÚMENES}

¿Quiénes son los servidores públicos plurinacionales? ¿Se ha democratizado el acceso a la burocracia boliviana en la última década? Si fuera así, ¿esto ha des-institucionalizado el aparato 
público? Este artículo presenta algunos hallazgos de una investigación sobre la burocracia del gobierno de Evo Morales (2006-2016). A partir de tres casos de estudio se intenta identificar cómo se traduce la llamada "emergencia indígena" en la composición social del Estado y qué repercusiones tiene tanto en el aparato público plurinacional, como en procesos de movilidad social y autoafirmación étnica indígena desde el 2006.

Quels sont les nouveaux serviteurs de l'État plurinational ? Y a-t-il eu une démocratisation de l'accès à la bureaucratie bolivienne durant cette dernière décennie ? Si tel était le cas, cela a-t-il des-institutionnalisé l'appareil public ? Cet article présente quelques nouveautés dans le cadre d'une recherche plus large sur la bureaucratie du gouvernement d'Evo Morales (2006-2010). À partir de trois études de cas, il s'agit d'identifier de quelle façon se traduit «l'émergence indigène » dans la composition sociale de l'État et quelles répercussions cela a-t-il tant dans l'appareil public plurinational que dans les processus de mobilité sociale et d'auto-affirmation ethnique indienne depuis 2006.

\section{ÍNDICE}

Mots-clés: fonctionnaires publics, mobilité sociale, démocratisation, indigène, État, Morales (Evo), Bolivie

Palabras claves: funcionarios públicos, movilidad social, democratización, indígena, Estado, Morales (Evo), Bolivia

\section{AUTOR}

\section{XIMENA SORUCO SOLOGUREN}

Universidad San Andrés (UMSA) (La Paz) y Centro de Investigaciones Sociales (CIS), Vicepresidencia del Estado Plurinacional de Bolivia. 